\title{
Modelling the Employment in Tourism - Case Study of Croatia
}

\author{
Maja Mamula $^{1} \&$ Kristina Duvnjak ${ }^{1}$ \\ ${ }^{1}$ Faculty of Tourism and Hospitality Management, University of Rijeka, Opatija, Croatia \\ Correspondence: Maja Mamula, Faculty of Tourism and Hospitality Management, Primorksa 42, Ika, 51410 Opatija, \\ Croatia. Tel: 00-385-51-294-684.
}

Received: April 3, 2017

Accepted: April 20, 2017

Online Published: May 3, 2017

doi:10.5430/ijba.v8n3p37

URL: https://doi.org/10.5430/ijba.v8n3p37

\begin{abstract}
According to the data on the share of employees in the category Hotels and similar accommodation in the total employees (16.6\% in 2015), it can be concluded that this percentage share is quite significant. In this paper the number of employees in tourism (in the category Hotels and similar accommodation) is modelled and predicted on the basis of monthly data from the period 2005 to 2015, collected from the First Release of the Croatian Bureau of Statistics. Taking into consideration the seasonal character of the phenomenon being analysed, taking into account the criteria of reliability of demonstrated forecasts, in this study following methods were used: the seasonal naive models, Holt - Winters Model trend seasonality exponential smoothing and Holt- Winters no seasonal exponential smoothing model. All obtained results were compared by forecasting error Mean Absolute Percentage error (MAPE). The obtained results indicate that forecasting methods which take into account the seasonal character of the phenomenon result in smaller forecasting error, and more reliable estimate, compared to models which don't take into account the character of the phenomenon being analysed.
\end{abstract}

Keywords: tourism, employment in tourism, seasonality, naive models, Holt-Winters model, forecasting errors

\section{Introduction}

Croatian accession to the European Union in 2013 has opened up a market of approximately 750 million potential tourists and brought Croatia more closer to the most successful tourist world destinations. Due to globalisation trends and the significant growth of the world tourism, the analysing of the Croatian tourism sector became the condition sine qua non of successful development strategies. Although, the importance of tourism for Croatian economic development is not questionable, the issue of employment in the tourism sector and its pronounced seasonality have not been taken into serious account in detailed quantitative studies and discussions.

Due to the importance of the tourism sector for Croatian economic development a short outline of the most important tourism and hospitality indicators is given. Data are taken from the Croatian Bureau of Statistics. All data refer to the category Hotels and similar accommodation and relate to the period from 2005 to 2015. Analysis of the importance that tourism has for the Croatian economy can be summarized in the following table.

Table 1. Croatian tourist image (2000 to 2015 year)

\begin{tabular}{cccccc}
\hline Year & Total number of nights & $\begin{array}{c}\text { Number of } \\
\text { overnight } \\
\text { stays in hotel }\end{array}$ & $\begin{array}{c}\text { The total } \\
\text { number of } \\
\text { beds }\end{array}$ & $\begin{array}{c}\text { The total } \\
\text { number of beds } \\
\text { in hotels }\end{array}$ & $\begin{array}{c}\text { \% share of } \\
\text { hotels in total } \\
\text { accommodation }\end{array}$ \\
\hline 2005 & 51421 & 14960 & 909210 & 115776 & $12.73 \%$ \\
2006 & 53007 & 14764 & 925882 & 113437 & $12.25 \%$ \\
2007 & 56005 & 15070 & 944076 & 115631 & $12.24 \%$ \\
2008 & 57103 & 15145 & 968610 & 116904 & $12.07 \%$ \\
2009 & 56300 & 14176 & 969726 & 121086 & $12.49 \%$ \\
2010 & 56416 & 15045 & 909951 & 122879 & $13.50 \%$ \\
\hline
\end{tabular}




\begin{tabular}{llllll}
\hline 2011 & 60354 & 16145 & 934564 & 128003 & $13.69 \%$ \\
2012 & 62743 & 16521 & 880170 & 129151 & $14.67 \%$ \\
2013 & 64818 & 16751 & 961896 & 132755 & $13.80 \%$ \\
2014 & 66484 & 16619 & 977414 & 132998 & $13.60 \%$ \\
2015 & 71605 & 17539 & 1002252 & 164730 & $16.43 \%$ \\
\hline
\end{tabular}

The total number of overnight stays, like the most of economic trends, raised to the emergence of the global crisis in 2008. Then, the total number of overnight stays in total and in hotels as well, began to decline until 2011, when continued to grow again.

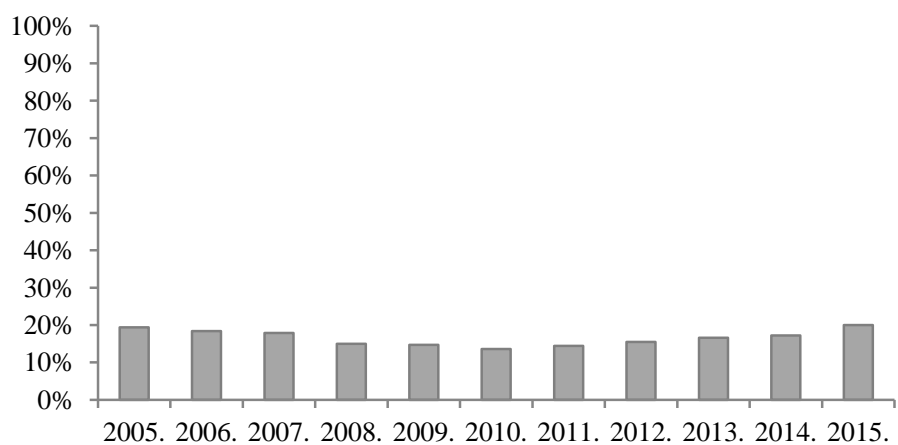

Figure 1. The share of tourism in GDP in the Republic of Croatia (2005-2015)

Once dependent on tourism, countries like Spain and Greece now have "fallen" on the scale of dependence on tourism. The highest first place went to Croatia according to research conducted in 2015. With a $20 \%$ share of tourism revenues in GDP in 2015, Croatia became the most dependent member on tourism in the European Union.

Table 2. The share of employees in the category Hotels and similar accommodation in the total number of employees

\begin{tabular}{cccc}
\hline \multirow{2}{*}{ Year } & \multicolumn{3}{c}{ Share in the total number of employees $(\%)$} \\
\cline { 2 - 4 } & Total & In the legal entities & $\begin{array}{c}\text { In the craft businesses and } \\
\text { free professions }\end{array}$ \\
\hline 2005 & 5.9 & 3.7 & 15.5 \\
2006 & 5.9 & 3.6 & 15.6 \\
2007 & 6.0 & 3.4 & 15.4 \\
2008 & 6.0 & 3.9 & 15.3 \\
2009 & 5.8 & 3.8 & 15.6 \\
2010 & 6.0 & 4.0 & 15.9 \\
2011 & 6.1 & 4.1 & 16.3 \\
2012 & 6.1 & 4.1 & 16.4 \\
2013 & 6.3 & 4.4 & 16.8 \\
2014 & 6.4 & 4.6 & 16.6 \\
\hline
\end{tabular}

According to the data on the share of employees in the category Hotels and similar accommodation in the total employees, it can be concluded that this percentage share is quite significant. From 2005 until 2015, the total number of employees is constantly increasing, with the exception of 2009, when imperceptible decline is recorded.

Taking into consideration the importance of tourism for the economic development of the Republic of Croatia, and as well as the importance of the number of employees in tourism, in this paper authors analysed the total number of 
employees in tourism, specifically, the total number of employees in the category Hotels and similar accommodation using different methods of extrapolation.

\section{Literature Review}

Research of exponential smoothing models and their application date back to the 1950s of the last century. After the original book of Brown and Holt in 50s of the last century, many authors were trying to create and discover new methods and variations of models. Realizing the meaning of exponential smoothing as a pragmatic approach, they began to create guidelines for methodology of exponential smoothing. (Gardner and McKenzie, 1985, 1) A few years later, the same authors continued research on seasonal phenomena and exponential smoothing of them, and confirmed that the Holt- Winters method, although complex in all its variations, is effective in analysing the phenomenon of seasonal character. (Gardner and McKenzie, 1989, 373)

The need for the use of exponential smoothing in order to forecast the effects of tourism was not represented as in its beginnings, and there weren't so many authors who advocated their research to such phenomenon (Sheldon, 1993, 13). Tourism demand is used as the most common measure of use of the products and services in tourism. The most of tourism demand definitions derive from the economic demand; a need for having a product or service and of the possibility of their purchase. For this reason, the tourist demand research usually uses measures such as tourist arrivals and tourist expenditure, and these measures are used for forecasting (Song, Li et al., 2010, 64). Taylor pointed out that multiplicative trend exponential smoothing has received very little attention in the literature. (Taylor, 2003, 1)

However, some studies were conducted on the topic of exponential smoothing and forecasting tourism. In some studies, Holt- Winters method of triple exponential smoothing, showed a representative results of research the phenomenon of seasonal character (Baldigara and Mamula, 2015, 30). Indeed, according to Mamula's research (Mamula, 2015) the Holt-Winters method of triple exponential smoothing showed better results compared to the seasonal naive model (according to the absolute average percentage error).

Presented literature review shows that the most of former papers investigated and defined the methods of extrapolation and the possibility of their application in seasonally characterised analysis. This research confirms that smaller number of papers is dedicated to analysis of economic phenomena, more specifically the phenomena in tourism, and especially the number of employees in tourism. Considering that, in this research the extrapolation methods were used in modelling and forecasting the number of employees in tourism. Also, considering that this topic has not been significantly researched by domestic and foreign scientist so far, it can be concluded that the scientific contribution of this paper is in application of specific theoretical settings in practice.

\section{Data and Methodology}

Starting with the assumption that tourism is the most propulsive economic sector in Croatia, and assuming its significant development impact, the paper analyses the issues of the number of employees in the Croatian tourism sector, which is characterised by a pronounced seasonality.

Analysed data are monthly, covers the period from 2005 to 2015 and are taken from the First Releases of the Croatian Bureau of Statistics. Figure 2 shows the monthly number of employees in the Croatian tourism sector in the category Hotels and similar accommodation.

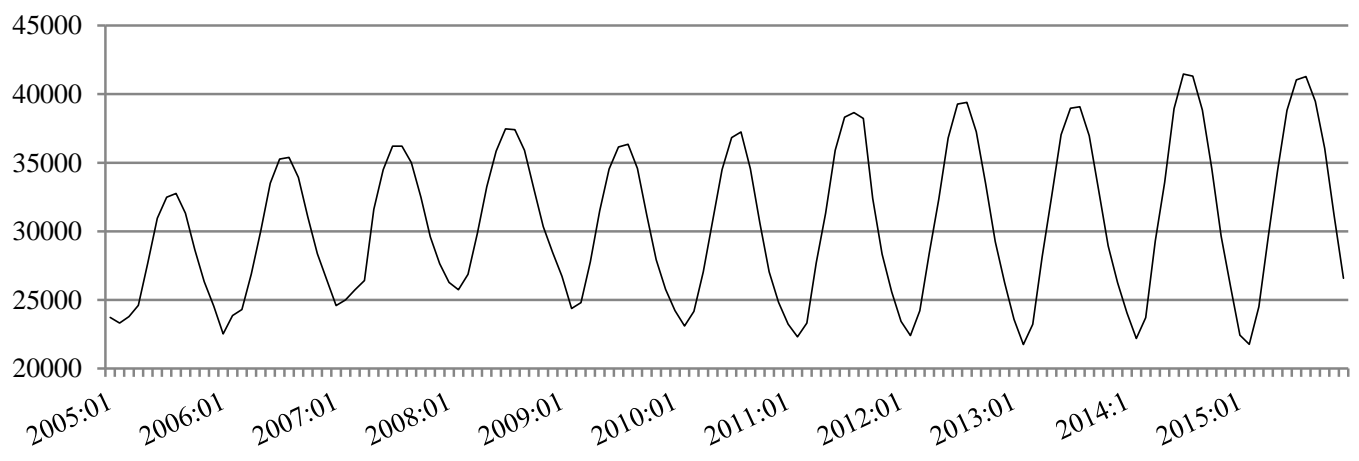

Figure 2. The number of employees in the Croatian tourism sector in the category Hotels and similar accommodation 
As shown in the above figure the number of employees in the Croatian tourism sector is characterised by a high level of seasonality. The analysed empirical time-series shows also a trend component. It is clearly shown that the seasonal patterns are rather consistent over the analysed period. The number of employees in the tourism sector is at its maximum levels in the summer period from July to August, with a drastic fall in the period from October to May. As shown in Figure 2, the number of employees grew until 2009, to the beginning of the recession, when it starts to decline. Finally the upward trend started again in 2011.

Considering the data presented in Figure 2, in modelling of the number of employees must be applied a method which takes into account seasonal character. Among the existing methods of extrapolation Holt-Winters triple exponential smoothing method form was selected. In order to compare the effectiveness of that method the number of employees is modelled with seasonal naive model and Holt-Winters double exponential smoothing method also, wherein the data were previously seasonally adjusted.

The following section describes the theoretical concepts of the modelling techniques used in this study and the essentials of the selected forecasting error for evaluating the forecasting accuracy.

\subsection{The Seasonal Naive Model}

The seasonal naive model assumes that the next period's value is equal to the value of the same period in the previous year. The seasonal naive model is expressed as follows:

$$
F_{t}=A_{t-m}
$$

where:

$$
\begin{aligned}
F & - \text { forecast value } \\
A & - \text { actual value } \\
t & - \text { some period time } \\
m & - \text { number of periods in a year }
\end{aligned}
$$

This model is also known as no - change model, and it's usually used as benchmark forecast; for comparison with the forecast generated by other more sophisticated forecasting methods. (Baldigara and Koić, 2015, 123)

\subsection{The Holt-Winters Trend and Seasonality Model}

The Holt-Winters multiplicative model is appropriate for time series with a linear time trend and multiplicative seasonal variations. This model employs triple exponential smoothing: one equation for the level, one for the trend and one for the seasonality. The smoothed series is given by following equations: (Note 1)

$$
\hat{Y}_{t+k}=(a+b k) c_{t+k}
$$

where:

$$
\begin{aligned}
a & - \text { permanent component (intercept) } \\
b & - \text { trend } \\
c_{t} & - \text { multiplicative seasonal factor }
\end{aligned}
$$

Coefficients mentioned above are defined by the following recursions:

$$
\begin{gathered}
\text { Level } \\
\text { Trend } \\
\text { Seasonal }
\end{gathered} \begin{gathered}
a(t)=\alpha \cdot \frac{Y_{t}}{c_{t}(t-s)}+(1-\alpha)(\alpha(t-1)+b(t-1)) \\
\quad c_{t}(t)=\gamma \frac{Y_{t}}{a(t)}+(1-\gamma) c_{t}(t-s)
\end{gathered}
$$

Where $0<\alpha, \beta, \gamma<1$ are the damping factors and $\mathrm{s}$ is the seasonal frequency. Forecasts can be computed by:

$$
\hat{Y}_{t+}=(a(T)+b(T) k) c_{T+k-s}
$$

where the seasonal factors are used from the last s estimates.

\subsection{The Holt-Winters No Seasonal Model}

The Holt-Winters no seasonal (two parameters) model is appropriate for series with linear time trend and no seasonal variation. It is similar to the double smoothing method in that both generate forecasts with linear trend and no seasonal component, but double smoothing method is more parsimonious since it uses only one parameter, while 
Holt-Winters no seasonal model is a two parameter model. Two coefficients used in Holt-Winters no seasonal model can be computed by the following recursions:

$$
\begin{array}{cc}
\text { Level } & a(t)=\alpha y_{t}+(1-\alpha)(a(t-1)+b(t-1)) \\
\text { Trend } & b(t)=\beta(a(t)-a(t-1))+(1-\beta b(t-1))
\end{array}
$$

Where $0<\alpha, \beta<1$ are the damping factors. Forecasts can be computed by:

$$
\hat{Y}_{T+k}=a(T)+b(T) k
$$

This forecasts lie on a linear trend with intercept $a(T)$ and slope $b(T)$.

When speaking about exponential smoothing, it is important to mention smoothing constants which determine the sensitivity of forecasts to changes in time series. "Large values of $\alpha$ make forecast more responsive to more recent levels, whereas smaller values have dumping effect. Large values of $\beta$ have a similar effect, emphasizing recent trend over older estimates of trend." (Handanhla, 2013, 348).

\subsection{The Mean Absolute Percentage Error}

Although there are a number of forecasting errors that can be used for accuracy evaluation, in this study Mean Absolute Percentage Error is used. The Mean Absolute Percentage Error (MAPE) is expressed in generic percentage terms and it is computed by the following expression:

$$
M A P E=\frac{1}{n} \sum_{t=1}^{n}\left|\frac{\left(A_{t}-F_{t}\right)}{A_{t}}\right| \cdot 100
$$

where:

$$
\begin{aligned}
& \text { t } \quad \text { - some time period } \\
& \text { A }- \text { actual value of the variable being forecasted } \\
& \text { F }- \text { forecast value }
\end{aligned}
$$

The reason why MAPE is considered as good accuracy measure is that this measure doesn't depend on the magnitudes of the variables being predicted (Mamula, 2015, 107). MAPE is a simple measure that permits to compare the accuracy of different models, with different time periods and numbers of observations.

\section{Empirical Results and Discussion}

In this section the comparison of the results obtained using the seasonal naive model, Holt-Winters trend and seasonality model and Holt-Winters no seasonal model in analysis of the number of employees in Croatian tourism sector in the period from January 2005 to December 2015 is discussed.

\subsection{The Seasonal Naive Model}

The Seasonal Naive model is defined under the assumption that the number of employees in tourism at current time $t$ is the same as the value at time $t-12$. The MAPE of 1.38 for the Seasonal Naive model indicates a high accuracy in forecasting the empirical data.

\subsection{The Holt-Winters Trend and Seasonality Model}

In modelling the empirical data of the number of employees in Croatian tourism sector in the analysed time period the multiplicative Holt-Winters model is used. The results are reported in Table 3.

Table 3. Holt-Winters trend and seasonality results for the number of employees in Croatian tourism (2005-2015)

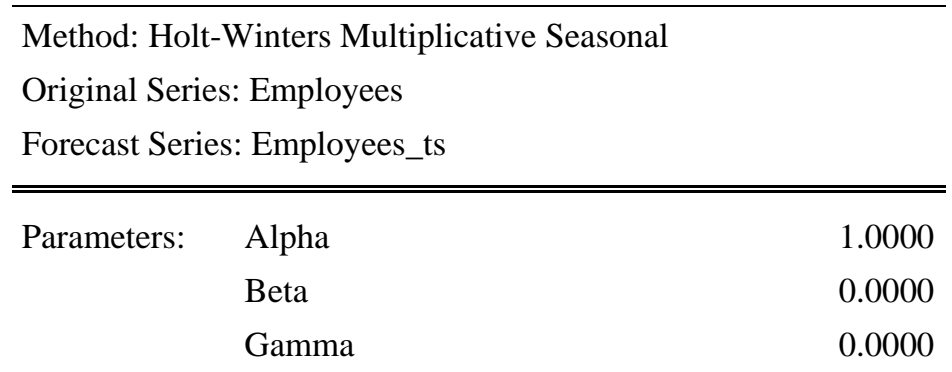




\begin{tabular}{|c|c|c|c|}
\hline Sum of Squared Residuals & & & 88302844 \\
\hline Root Mean Squared Error & & & 817.9003 \\
\hline End of Period Levels: & Mean & & 31080.51 \\
\hline & Trend & & 39.61458 \\
\hline & Seasonals: & 2015M01 & 0.797328 \\
\hline & & $2015 \mathrm{M} 02$ & 0.769751 \\
\hline & & $2015 \mathrm{M} 03$ & 0.806485 \\
\hline & & 2015M04 & 0.914976 \\
\hline & & $2015 \mathrm{M} 05$ & 1.043426 \\
\hline & & 2015M06 & 1.167887 \\
\hline & & $2015 \mathrm{M} 07$ & 1.232395 \\
\hline & & $2015 \mathrm{M} 08$ & 1.235723 \\
\hline & & 2015M09 & 1.177517 \\
\hline & & $2015 \mathrm{M} 10$ & 1.058637 \\
\hline & & $2015 \mathrm{M} 11$ & 0.940580 \\
\hline & & $2015 \mathrm{M} 12$ & 0.855295 \\
\hline
\end{tabular}

In the Table 3, the results of smoothing procedure are presented. In the first part the estimated parameters and forecasting errors are displayed. The smoothing procedure resulted with the following smoothing constants $\alpha=1, \beta=0$ and $\gamma=0$. In general, the very small value of $\beta$ means that the model assumes little changes in the trend from one period to next, and those models are trying to estimate long-term trend. The zero values for $\beta$ and $\gamma$ in this paper mean that trend and seasonal components are fixed; not changing. The designed model minimizes the sum of squares and shows a highly accurate performance in modelling the empirical data with a MAPE of 2.04.

\subsection{The Holt-Winters No Seasonal Model}

In the following table results of modelling empirical time series of the number of employees by the Holt-Winters no seasonal model are presented. Considering that the data emphasises its seasonal component, before modelling data were seasonally adjusted by the ratio to moving average (multiplicative) method.

Table 4. Holt-Winters no seasonal results for the number of employees in Croatian tourism (2005-2015)

\begin{tabular}{lr}
\hline Included observations: 132 & \\
Method: Holt-Winters No Seasonal & \\
Original Series: Employees_sa & \\
Forecast Series: Employees_sa_ns & 1.0000 \\
\hline \hline Parameters: Alpha & 0.0000 \\
\multicolumn{1}{c}{ Beta } & 99245286 \\
Sum of Squared Residuals & 867.0976 \\
Root Mean Squared Error & 30386.00 \\
\hline \hline End of Period Levels: $\quad$ Mean & 0.070209 \\
\hline
\end{tabular}

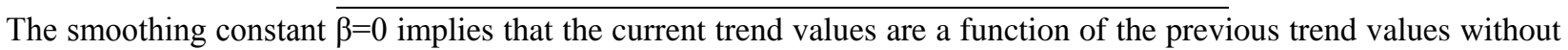
considering the difference in the smoothed values. The designed model shows a good accurate performance in modelling the empirical data with a MAPE of 16.11 . 
Comparison of the predicted values for all three models is shown in the following figure.

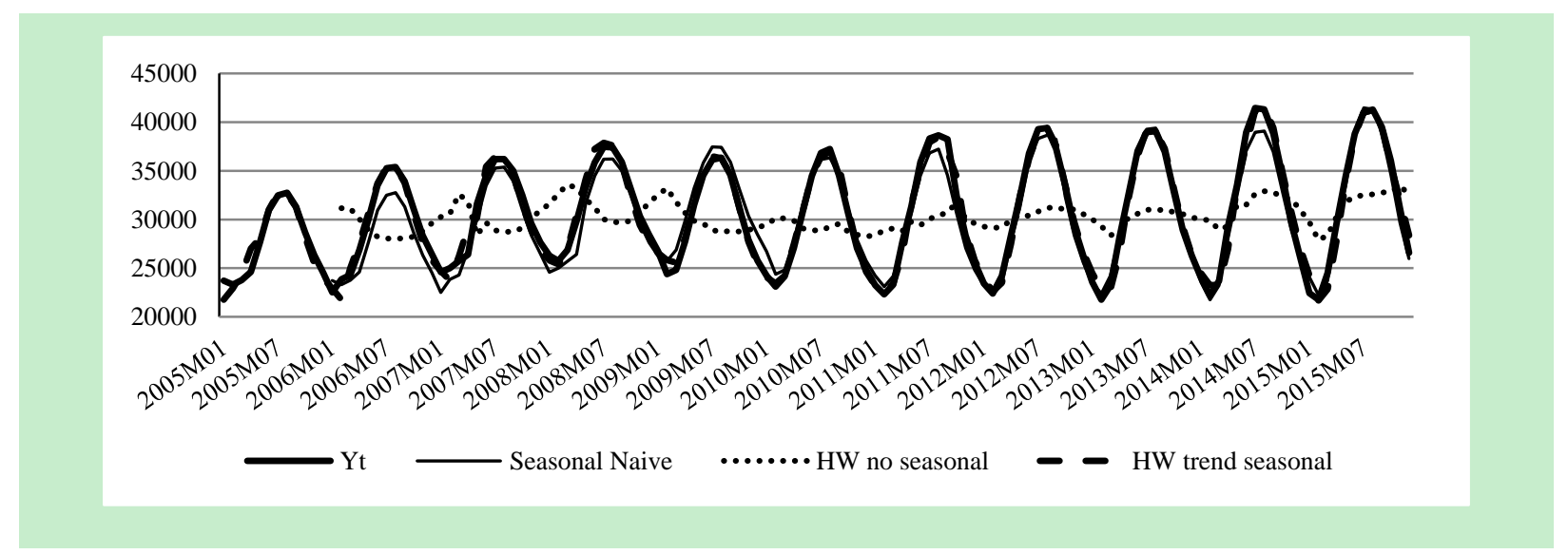

Figure 3. Modelling of the number : comparison of different time series models

The three models used to model the number of employees in category Hotels and similar accommodation fit the general movement of the analysed series during the entire period.

Table 5 reports the MAPE values obtained using the three extrapolative models.

Table 5. Errors of selected forecasting models

\begin{tabular}{cc}
\hline Model & MAPE value \\
\hline The seasonal naive & 1.38 \\
The Holt-Winters trend seasonality exponential smoothing model & 2.04 \\
The Holt-Winters no seasonal exponential smoothing model & 16.11 \\
\hline
\end{tabular}

Table 5 shows that the seasonal naive model showed the best forecasting accuracy. However, it was stated earlier that the naive models are usually used as benchmark to other models. Furthermore, according to the criteria of naive benchmarking and other models, the Holt-Winters trend seasonal model's MAPE is bit higher than a naive model MAPE, but both still show highly accurate forecasting performance (according to Baggio and Klobas criteria, 2011, 151).

The Holt-Winters no seasonal model has the highest MAPE (MAPE=16.11) which proved that this model is not appropriate for modelling and forecasting time series which occur seasonal component.

Considering above facts, the main hypothesis of this research can be accepted as true; when analysing, modelling and forecasting time series which occur seasonal component the seasonal character of phenomenon must be respected.

\section{Conclusion}

At the beginning of the study the authors seek to highlight the role of tourism for the economic development of the Republic of Croatia showing the basic tourism indicators. Finally, the number of employees in tourism, concretely in category Hotels and similar accommodation were modelled and predicted by selected extrapolation methods. Taking into account the seasonal nature of the phenomenon being analysed and reliability criteria of demonstrated forecasts, following methods were used in the paper: seasonal naive model, Holt-Winters Model trend seasonality model and Holt- Winters no seasonal model. Predicted values were compared by forecasting error Mean Absolute Percentage error (MAPE). The results indicated which forecasting methods that take into account the seasonal nature of the phenomenon to be analysed, result in smaller forecasting error and reliable assessment, compared to models which do not take into account the nature of the phenomenon being analysed. 
The significance of this research is in the fact that in the Republic of Croatia exists small number of research on the topic of employment in the tourism sector, especially its modelling and forecasting. Therefore, this paper can be considered as a good starting point for similar future research.

\section{Acknowledgments}

This paper has been financially supported by the University of Rijeka, for the project ZP UNIRI 5/16.

\section{Refrences}

Baggio, R., \& Klobas, J. (2011). Quantitative methods in tourism. Bristol-Buffalo-Toronto: Channel View Publication.

Baldigara, T., \& Koić, M. (2015). Modelling occupancy Rates in Croatian Hotel Industry. International Journal of Business Administration, 6(3), 121-131. https://doi.org/10.5430/ijba.v6n3p121

Baldigara, T., \& Mamula, M. (2015). Modelling international tourism demand using seasonal ARIMA models. Tourism and Hospitality Management 21(1) 19-31.

Box, G. E. P., \& Jenkins, M. (1976). Time Series Analysis: Forecasting and Control. San Francisco: Holden- Day.

Čizmešija, M., \& Sorić P. (2011). Statističke metode za poslovno upravljanje. Zagreb: Element.

Cooper, Ch., Fletcher, J., Fyall, A., Gilbert, D., \& Wanhill, S. (2008). Tourism: Principles and Practice. Financial Times/ Prentice Hall,

Croatian Bureau of Statistics. (2013). First Releases. Retreived January 15, 2017, from http://www.dzs.hr/Hrv_Eng/publication/2017/04-03-01_01_2017.htm

EViews 9 Users Guide 1. ISI Global Inc. March 2016.

Gardner Jr., Everette, S., \& Ed, McKenzie. (1985). Exponential Smoothing: The state of art. Journal of Forcasting, 4(1), 1-28. https://doi.org/10.1002/for.3980040103

. (1989). Note- Seasonal Exponential Smoothing with Damped Trends. Management Science, 35(3), 372-376. https://doi.org/10.1287/mnsc.35.3.372

Gerbing, D. (2016). Time Series Components. School of Business Administration: Portland State University. Retrieved December, 2016, from http://web.pdx.edu/ gerbing/515/Resources/ts.pdf

Handahal V. Ravinder. (2013). Determining the Optimal Values of Exponential Smoothing Constants - Does Solver Really Works?. American Jorunal of Business Education, 6(3), 347-360.

Hyndman, R. J., \& Koehler, A.B. (2005). Another Look at Measures of Forecat Accuracy. International Journal of Forecasting, 22(4), 1-18. https://doi.org/10.1.1.154.9771.

Kožić, I. (2013). Kolika je sezonalnost turizma u Hrvatskoj? Ekonomski vjesnik, XXVI(2), 470-480.

Mamula, M. (2014). Kvantitativne metode u prognoziranju turističke potražnje. Rijeka: vlastita naklada.

Mamula, M. (2015). Modelling and Forcasting International Tourism Demand- Evaluation of Forecasting Performance. International Journal of Business Administration, 6(3), 102-112. https://doi.org/10.5430/ijba.v6n3p102

Mladenović, Z., \& Nojković, A. (2015). Primenjena analiza vremenskih serija. Beograd: Ekonomski fakultet Univerziteta u Beogradu.

Sheldon, P. J. (1993). Forecasting Tourism: Expenditure versus Arrivals. Journal of Travel Research, 32(1), 13-20. https://doi.org/10.1177/004728759303200103

Song, H., Gang, L., Witt, S., \& Baogang, F. (2010). Tourism demand modelling and forecasting: How should demand be measured? Tourism Economics, 16(1), 63-81. https://doi.org/10.5367/000000010790872213

Taylor, J. W. (2003). Exponential smoothing with a damped multiplicative trend. International Journal of Forecasting, 19(4), 715-725. https://doi.org/10.1016/S0169-2070(03)00003-7

\section{Note}

Note 1. Adapted from EViews 9 Users Guide 1. ISI Global Inc. March 2016. 